\title{
Dukungan Keluarga Berhubungan dengan Asupan Energi Anak Retardasi Mental di SLB Negeri 01 Kabupaten Bantul
}

\author{
Bunga Astria Paramashanti ${ }^{1}$, Arief Rakhman², Lia Endriyani² \\ ${ }^{1}$ Prodi Ilmu Gizi Universitas Alma Ata Yogyakarta \\ ${ }^{2}$ Prodi Ners Universitas Alma Ata Yogyakarta \\ Jalan Ringroad Barat Daya Tamantirto, Kasihan, Bantul, Yogyakarta \\ Email: pshanti.bunga@gmail.com
}

\begin{abstract}
Abstrak
Penderita Retardasi Mental, banyak yang kurang mendapat dukungan dan pengasuhan yang baik dari keluarganya, keluarga terkesan menutup diri akibat malu mempunyai anggota keluarga dengan kondisi tersebut. Dukungan keluarga dalam hal ini mempunyai peranan yang sangat penting dalam perkembangan anak, yang dapat berpengaruh pada aspek fisik, perawatan diri sendiri, komunikasi, bersosialisasi, dan mental emosional. Anak memiliki risiko malnutrisi apabila kebutuhan nutrisi yang menunjang proses tumbuh kembangnya tidak tercukupi dengan baik. Tujuan penelitian ini adalah untuk mengetahui hubungan dukungan keluarga dengan asupan energi anak retardasi mental di SLB Negeri 01 Bantul tahun 2016, Yogyakarta. Penelitian ini merupakan penelitian kuantitatif dengan rancangan cross sectional. Populasi dalam penelitian ini adalah seluruh anak retardasi mental di SD-SMA. Sampel pada penelitian ini berjumlah 66 subjek. Pengambilan data menggunakan kuesioner dan systematic random sampling. Data dianalisis menggunakan uji statistik Kendal Tau. Hasil penelitian didapatkan bahwa subjek yang mempunyai dukungan keluarga yang baik dan asupan energi yang cukup berjumlah 27 subjek (40,9\%), subjek yang mempunyai dukungan keluarga cukup dan asupan energi cukup berjumlah 13 subjek (19,7\%), sedangkan dukungan keluarga yang cukup dan asupan energi kurang sebanyak 10 subjek (15,2\%). Berdasarkan analisis Kendal Tau diperoleh nilai $p$-value 0,001 $(p<0,05)$ yang berarti ada hubungan yang signifikan antara dukungan keluarga dengan asupan energi pada anak retardasi mental di SLB N 01 Bantul Yogyakarta. Oleh karena itu, pemberian motivasi dan edukasi kepada orangtua untuk memberikan dukungannya, khususnya pada asupan makan anak sangat diperlukan.
\end{abstract}

Kata Kunci: retardasi mental, dukungan keluarga, anak, asupan energi

\section{Family Support was Related with Energy Intake in Children with Mental Retardation in SLB N 01 Bantul District}

\begin{abstract}
People with Mental Retardation mostly do not get proper support and care from their families. It is likely that families keep distance from public due to embarrasement of having a family member with such condition. Family support in this term plays an essential role in terms of child growth, which may be influential to physical aspect, self-care, communication, socialization, mentality, and emotion. Children will be malnourished if the nutrition necessary to support growth process is not fulfilled appropriately. The purpose of this research was to identify the relation between family support and energy intake in children with mental retardation in SLB N 01 of Bantul, Yogyakarta. This research was a quantitative research with cross sectional design. Population in this research was all children with mental retardation since the age of elementary school until senior high school. Samples in this research were 66 subjects. Data collection used questionnaires and systematic random sampling. Data was analyzed by using Kendal Tau statistical test. Results found that respondents who had good family support and sufficient energy intake were 27 subjects (40.9\%), subjects who had fair family support and sufficient energy intake were 13 subjects (19.7\%), subjects with sufficient family support and insufficient energy intake were 10 subjects (15.2\%). According to Kendal Tau analysis, it was showed that $p$-value was $0.001 \quad(p<0.05)$ which described that there was a significant relation between family
\end{abstract}


support and energy intake in children with mental retardation in SLB N 01 of Bantul, Yogyakarta. Therefore, it is essential to provide motivation and education for parents with mentally retarded children, especially on child food intake.

Keywords: mental retardation, family support, child, energy intake

Info Artikel:

Artikel dikirim pada 22 Juli 2016

Artikel diterima pada 31 Oktober 2016

DOI : http://dx.doi.org/10.21927/jnki.2016.4(3).163-168

\section{PENDAHULUAN}

Anak berkebutuhan khusus (ABK) merupakan gangguan fisik, mental, intelektual, atau sensoris dalam jangka panjang pada anak-anak hingga berusia 18 tahun (1). Dalam hal ini, retardasi mental adalah kondisi perkembangan otak yang tidak lengkap, dikarakterisasi oleh gangguan kemampuan perkembangan yang berkontribusi pada perkembangan kognitif, bahasa, motorik, dan sosial (2). Retardasi mental ini kemudian dibagi menjadi beberapa kategori berdasarkan tingkat keparahan (ringan, sedang, dan tinggi) atau berdasarkan etiologi (3).

Secara global, prevalensi retardasi mental adalah $1 \%$ dimana prevalensi ini lebih tinggi pada anak-anak dan remaja $(4,5)$. Di Indonesia, retardasi mental menempati urutan ke-4 di antara masalah gangguan kecacatan lainnya (6). Adapun jumlah penderita retardasi mental di Daerah Istimewa Yogyakarta sebesar 9.251 orang pada tahun 2010 (7).

Retardasi mental dikaitkan dengan keterbatasan dari berbagai hal, salah satunya adalah masalah gizi. Masalah gizi memiliki hubungan timbal balik pada ABK, baik sebagai penyebab maupun sebagai dampak. Anak berkebutuhan khusus yang tidak tercukupi asupan energinya dari makanan akan lebih berisiko untuk menderita kondisi sekunder lain seperti kurang gizi, defisiensi zat gizi mikro, dan gizi buruk (8). Selain itu, ABK juga cenderung memiliki risiko kehilangan zat gizi dan angka kecukupan gizi yang lebih tinggi (9). Oleh karena itu, pemenuhan asupan energi dari makanan pada ABK, termasuk anak dengan retardasi mental sangat diperlukan untuk mencapai status gizi dan kesehatan yang optimal.

Dukungan keluarga juga perlu diperhatikan dalam perkembangan dan perlindungan bagi anak, khususnya anak dengan retardasi mental $(10,11)$. Dukungan keluarga dapat memengaruhi perilaku makan pada anak-anak, seperti melakukan interaksi sosial pada saat makan, memberikan penghargaan saat anak makan dengan baik, dan membentuk pola makan yang baik sejak dini $(12,13)$. Di sisi lain, ABK memiliki masalah kesulitan makan (feeding difficulty) yang akan berdampak pada rendahnya asupan zat gizi dan status gizinya (14). Hal ini mengindikasikan bahwa dukungan keluarga sangat penting untuk mendukung asupan zat gizi pada anak-anak tersebut.

Sejumlah studi menunjukkan adanya hubungan yang signifikan dari peran atau dukungan keluarga dengan asupan zat gizi anak $(15,16)$. Selama ini penelitian tentang dukungan keluarga dan asupan zat gizi sudah banyak dilakukan, namun belum ada studi yang secara khusus meneliti pada subjek anak dengan retardasi mental. Oleh karena itu, penelitian ini bertujuan untuk untuk mengetahui hubungan dukungan keluarga dengan asupan energi pada anak retardasi mental di SLB Negeri 01 Bantul, Yogyakarta.

\section{BAHAN DAN METODE}

Jenis penelitian ini adalah kuantitatif dengan mengunakan metode observasional analitik. Rancangan dalam penelitian ini adalah crosssectional. Populasi dalam penelitian ini adalah seluruh siswa SD-SMA di SLB Negeri 01, Bantul, Yogyakarta, yang berjumlah 150 anak. Berdasarkan rumus perhitungan besar sampel, didapatkan jumlah minimal sampel sebesar 60 anak. Sampel diambil dengan menggunakan metode systematic sampling. Responden dalam penelitian ini adalah salah satu orangtua (wali) dari subjek.

Variabel utama dalam penelitian ini terdiri dari variabel bebas, yaitu dukungan keluarga dan variabel terikat, yaitu asupan energi. Data asupan energi diambil dengan menggunakan metode recall 2x24 jam oleh dua orang enumerator dengan latar belakang 
pendidikan ilmu gizi. Asupan energi kemudian dibagi menjadi dua kategori yaitu asupan energi yang sesuai ( $\geq 80-110 \%$ dari angka kecukupan gizi(AKG)) dan asupan energi yang tidak sesuai $(<80 \%$ dan $>110 \%$ dari $A K G)$.

Data dukungan keluarga diambil dengan menggunakan kuesioner berskala likert yang berisi tentang dukungan keluarga dalam bentuk informasional, penghargaan, instrumental, emosional, dan sosial. Data ini diambil oleh satu orang enumerator dengan latar belakang pendidikan ilmu keperawatan. Uji validitas dan reliabilitas telah dilakukan pada kuesioner.

Informed consent diberikan kepada orangtua responden sebagai persetujuan anaknya mengikuti penelitian ini. Persetujuan layak etik didapatkan dari Komisi Etik Penelitian Kesehatan Universitas Alma Ata dengan Nomor: KE/AA/V/16/EC/2016. Analisis statistik yang digunakan meliputi uji deskriptif statistik untuk menjelaskan karakteristik subjek dan uji korelasi Kendal-Tau untuk menjelaskan korelasi antara dua variabel utama (dukungan keluarga dan asupan energi).

\section{HASIL DAN BAHASAN}

Pada penelitian ini didapatkan 66 subjek anak dengan retardasi mental. Subjek merupakan anak dengan retardasi mental kategori ringan dan sedang. Tabel 1 menunjukkan bahwa sebagian besar subjek adalah siswa laki-laki $(66,7 \%)$ dan berusia $13-15$ tahun $(57,6 \%)$. Penelitian lain juga menunjukkan bahwa prevalensi retardasi mental lebih banyak terjadi pada anak laki-laki (3).

Tabel 1. Distribusi Subjek Berdasarkan Karakteristik

\begin{tabular}{lcc}
\hline \multicolumn{1}{c}{ Karakteristik Subjek } & $\mathbf{n}$ & $\%$ \\
\hline Usia Subjek & & \\
7-9 tahun & 8 & 12,1 \\
10-12 tahun & 7 & 10,6 \\
13-15 tahun & 38 & 57,6 \\
$\quad>15$ tahun & 13 & 19,7 \\
Jenis Kelamin Subjek & & \\
$\quad$ Laki-laki & 44 & 66,7 \\
$\quad$ Perempuan & 22 & 33,3 \\
Usia Wali & & \\
30-45 tahun & 26 & 39,4 \\
46-50 tahun & 35 & 53,0 \\
$\quad$ 50 tahun & 5 & 7,6 \\
Total & 66 & 100 \\
\hline
\end{tabular}

Sumber: Data Primer Tahun 2016
Tabel 2 menunjukkan distribusi variabel utama pada penelitian ini. Sebagian besar $(60,6 \%)$ subjek memiliki asupan energi yang sesuai atau $80-110 \%$ dari AKG. Hasil ini sejalan dengan penelitian di Seoul yang menghasilkan nilai rata-rata asupan energi pada anak retardasi mental di SLB, yaitu 94,1\% AKG. Hal ini menunjukkan bahwarata-rata asupan energi pada anakanaktersebutsesuaidengan kecukupan gizinya (17). Sedikit berbeda dengan hasil penelitian di Afrika selatan bahwa median asupan energi dari anakanak penyandang cacat sedikit di bawah kecukupannya (18).

Selain itu, dukungan keluarga juga sebagian besar $(65,1 \%)$ berkategori baik. Pada dasarnya, ABK memiliki hak-hak yang sama seperti anak-anak normal lainnya seperti hak untuk bertahan hidup; terhindar dari kekerasan dan eksploitasi; serta berpartisipasi secara utuh di dalam keluarga, sosial dan budaya. Seluruh hal ini menunjukkan peran yang sangat penting dari keluarga baik dalam bentuk asistensi maupun dukungan (10). Di beberapa populasi dengan budaya tertentu, ibu dari anak-anak dengan retardasi mental cenderung tidak termotivasi untuk memberikan asupan makan yang cukup sejak dini (seperti menghentikan pemberian ASI), serta memberikan makanan yang jumlahnya lebih sedikit dan tidak mengandung zat gizi yang kompleks apabila dibandingkan dengan pemberian makan pada anaknya yang normal atau tidak retardasi mental (1). Padahal dari segi pemenuhan asupan makan, orangtua berperan dalam membentuk kebiasaan makan anak sejak dini. Kebiasaan makan pada anak-anak berkembang sejak awal adanya paparan interaksi sosial di lingkungan tempat mereka makan. Kemampuannya untuk belajar dalam mengatur pola makan dan menerima segala bentuk makanan dipengaruhi oleh orangtua sebagai model yang dicontoh (13).

\section{Tabel 2. Distribusi Subjek Berdasarkan Dukungan} Keluarga dan Asupan Energi

\begin{tabular}{lcc}
\hline \multicolumn{1}{c}{ Variabel Utama } & $\mathbf{n}$ & $\%$ \\
\hline Asupan Energi & & \\
$\quad$ Sesuai $(\geq 80-110 \%$ AKG) & 40 & 60,6 \\
$\quad$ Tidak Sesuai $(<80 \%$ atau $>110 \%)$ & 26 & 39,4 \\
Dukungan Keluarga & & \\
$\quad$ Baik & 37 & 65,1 \\
$\quad$ Cukup & 26 & 39,4 \\
$\quad$ Kurang & 3 & 4,5 \\
Total & 66 & 100 \\
\hline
\end{tabular}

Sumber: Data Primer Tahun 2016 
Hasil analisis uji korelasi dengan menggunakan Kendall Tau- $b$ menunjukkan bahwa ada korelasi (agreement) antara variabel dukungan keluarga dan asupan energi $(p<0,01)$ dengan nilai koefisien korelasi 0,31 (95\% Cl: 0,20-0,39). Meskipun nilai koefisien korelasi yang dihasilkan dari uji tersebut tidak terlalu tinggi, namun hasil yang signifikan mampu menyimpulkan adanya korelasi positif di antara kedua variabel utama. Semakin tinggi dukungan keluarga, maka semakin sesuai pemenuhan asupan energinya. $\mathrm{Hal}$ ini menjelaskan bahwa dukungan keluarga berperan dalam pemenuhan energi yang sesuai dengan AKG. Orangtua berperan dalam memberikan dukungan pemenuhan gizi anak. Dukungan orangtua secara positif dikaitkan dengan skor asupan makan yang sehat dan berkorelasi secara negatif dengan skor asupan makan yang tidak sehat (15).

Salah satu penyebab lain dari rendahnya asupan pada anak retardasi mental adalah kesulitan makan (feeding difficulty). Kesulitan makan ini meningkatkan risiko malnutrisi pada anak retardasi mental, terlebih saat orangtua tidak memiliki waktu yang cukup untuk memberikan dukungannya (14). Sejumlah ABK memiliki beberapa hambatan lain dalam mengonsumsi makanan, seperti gangguan dalam mengunyah dan menelan. Hal ini berakibat pada rendahnya status gizi (1). Di Afrika Selatan, status gizi kurang menjadi salah satu masalah utama pada ABK (18).

Dukungan orangtua yang tidak adekuat ini cenderung mengarah pada pemenuhan kecukupan energi yang tidak sesuai dengan AKG, baik kurang maupun lebih. Sebuah studi di SLB di Jakarta menunjukkan tren prevalensi obesitas yang cukup besar pada anak retardasi mencapai 16\% (19). Prevalensi ini mengindikasikan bahwa ada kecenderungan kelebihan energi yang berdampak pada kejadian obesitas pada anak retardasi mental. Faktor-faktor lain yang dapat memengaruhi asupan energi pada anak retardasi mental meliputi jenis dan tingkat keparahan retardasi mental, disfagia, kehilangan zat gizi yang berlebihan dalam tubuh, refluks gastroesofageal, gangguan metabolisme energi, dan penggunaan obat antiepilepsi (20). Secara umum, pengetahuan, sikap, dan peran orangtua sebagai role model juga akan berpengaruh terhadap perilaku makan dan pemenuhan kebutuhan gizi pada anak $(21,22)$. Oleh karena itu, asupan energi pada anak retardasi mental perlu menjadi fokus untuk mencapai status gizi dan kesehatan yang optimal. Apabila tidak dilakukan dengan tepat, risiko untuk memiliki status gizi kurang atau lebih akibat asupan makan yang salah akan meningkat.

Dalam hal ini, respon orangtua terkait dengan asupan makan anak sangat penting untuk diperhatikan. Salah satunya adalah dengan meningkatkan kemampuan orangtua dalam pemberian makan pada anak (14). Secara khusus, untuk membantu mengoptimalkan pemenuhan energi anak, orangtua sebaiknya secara berulang menyediakan asupan makan dengan jumlah energi yang adekuat dan zat gizi yang berasal dari sumber makanan yang bervariasi (13). Oleh karena itu, dukungan gizi harus dijadikan sebagai bagian yang penting dalam manajemen pada anak dengan retardasi mental, tidak hanya untuk meningkatkan status gizinya tetapi juga untuk meningkatkan kualitas hidup pasien dan keluarganya (23).

Kecukupan energi dari makanan pada anak retardasi mental kemungkinan berbeda dengan anak normal, namun penelitian ini masih menggunakan AKG sebagai acuan dalam pemenuhan energinya. Hingga saat ini, perhitungan kebutuhan energi pada ABK masih belum tersedia secara khusus. Aktivitas fisik pun perlu diperhitungkan dalam penentuan kecukupan energi pada ABK (18).

Penelitian ini memiliki beberapa kelemahan lainnya. Penelitian ini hanya dilakukan pada satu SLB di Kota Yogyakarta sehingga hasilnya belum

Tabel 3. Korelasi Dukungan Keluarga dengan Asupan Enegi Anak Retardasi Mental

\begin{tabular}{|c|c|c|c|c|c|c|c|c|}
\hline \multirow{3}{*}{$\begin{array}{c}\text { Dukungan } \\
\text { Keluarga }\end{array}$} & \multicolumn{6}{|c|}{ Asupan Energi } & \multirow{3}{*}{$\mathrm{T}^{2}$} & \multirow{3}{*}{$p$} \\
\hline & \multicolumn{2}{|c|}{ Sesuai } & \multicolumn{2}{|c|}{ Tidak Sesuai } & \multicolumn{2}{|c|}{ Total } & & \\
\hline & $\mathbf{n}$ & $\%$ & $\mathbf{n}$ & $\%$ & $\mathbf{n}$ & $\%$ & & \\
\hline Baik & 27 & 40,9 & 10 & 15,2 & 37 & 56,1 & \multirow{4}{*}{$\begin{array}{c}0,31 \\
(0,20-0,39)\end{array}$} & \multirow[t]{4}{*}{$0,01^{*}$} \\
\hline Cukup & 13 & 19,7 & 13 & 19,7 & 26 & 39,4 & & \\
\hline Kurang & 0 & 0,0 & 3 & 4,5 & 3 & 4,5 & & \\
\hline Total & 40 & 60,6 & 26 & 39,4 & 66 & 100 & & \\
\hline
\end{tabular}

Sumber: Data Primer Tahun 2016 
dapat digeneralisasi pada populasi yang lebih luas lagi. Selain itu, desain yang digunakan merupakan desain penelitian cross-sectional sehingga hubungan sebab akibat tidak dapat ditarik sebagai kesimpulan. Meskipun begitu, penelitian ini merupakan penelitian yang masih tergolong baru karena selama ini belum ada penelitian yang mengkaitkan dukungan keluarga dengan pemenuhan asupan energi, khususnya pada anak dengan retardasi mental.

\section{SIMPULAN DAN SARAN}

Berdasarkan hasil penelitian yang telah dilakukan, maka dapat ditarik kesimpulan bahwa ada korelasi positif yang signifikan antara dukungan keluarga dan asupan energi pada anak retardasi mental, yaitu semakin tinggi dukungan keluarga, maka semakin sesuai pemenuhan asupan energinya. Dukungan keluarga sangat penting diberikan baik berupa interaksi sosial dengan anak, penghargaan terhadap anak, dan untuk membentuk pola makan yangbaiksejakdini,terutamapada ABK.

Dalam hal ini, upaya pemberian motivasi dan edukasi kepada orangtua diperlukan untuk memberikan dukungannya kepada anak dengan retardasi mental. Salah satunya adalah memberikan dukungan dalam memenuhi asupan energinya. Orangtua juga sebaiknya memantau kepadatan energi dari konsumsi makan anak dengan retardasi mental karena kurangnya perhatian terhadap asupan energi ini dapat meningkatkan risiko malnutrisi, baik gizi kurang maupun gizi lebih atau obesitas. Bagi peneliti selanjutnya, sebaiknya memperluas populasi penelitian, menggunakan desain penelitian yang lebih baik untuk membuktikan sebab-akibat pada variabel utama, menggunakan instrumen khusus tentang dukungan keluarga terhadap asupan makan anak, dan menggunakan referensi kecukupan energi yang khusus pada anak retardasi mental.

\section{RUJUKAN}

1. UNICEF. Children and Young People with Disabilities. Bangladesh; 2013.

2. World Health Organization (WHO). ICD-10 Guide For Mental Retardation. Geneva; 1996.

3. Armatas V. Mental Retardation: Definitions, Etiology,. J Sport Heal Res. 2009;1(June):112-22.

4. Maulik PK, Mascarenhas MN, Mathers CD, Dua T, Saxena S. Prevalence of intellectual disability: a meta-analysis of population-based studies. Res Dev Disabil [Internet]. 2011;32(2):419-36. Available from: http://www.ncbi.nlm.nih.gov/ pubmed/21236634.

5. McKenzie K, Milton M, Smith G, OuelletteKuntz H. Systematic Review of the Prevalence and Incidence of Intellectual Disabilities: Current Trends and Issues. Curr Dev Disord Reports [Internet]. 2016 Apr 15 [cited 2016 Nov 3];3(2):104-15. Available from: http://link.springer. com/10.1007/s40474-016-0085-7.

6. World Health Organization (WHO). Disability in the South-East Asia Region. 2013.

7. Kementerian Sosial RI. Pusat Data dan Informasi Kesehatan Sosial. 2012.

8. UNICEF. Stronger Together : Nutrition-Disability Links and Synergies - Briefing Note -. 2013.

9. Kerac M, Postels DG, Mallewa M, Alusine Jalloh A, Voskuijl WP, Groce N, et al. The interaction of malnutrition and neurologic disability in Africa. Semin Pediatr Neurol [Internet]. 2014 Mar [cited 2016 Nov 3];21(1):42-9. Available from: http:// www.ncbi.nlm.nih.gov/pubmed/24655404.

10. World Health Organization (WHO). Early Childhood Development and Disability. Geneva; 2012.

11. Neely-Barnes SL, Dia D a. Families of children with disabilities: A review of literature and recommendations for interventions. J Early Intensive Behav Interv [Internet]. 2008;5(3):93107. Available from: http://doi.apa.org/getdoi. cfm?doi=10.1037/h0100425.

12. Eliassen EK. The Impact of Teachers and Families on Young Children's Eating Behaviors. 2011.

13. Savage JS, Fisher JO, Birch LL. Parental Influece on Eating Behavior: Conception to Adolescence. J Law, Med Ethics. 2008;35(1):22-34.

14. Yousafzai AK, Filteau S, Wirz S. Feeding difficulties in disabled children leads to malnutrition: experience in an Indian slum. Br J Nutr [Internet]. 2007 Mar 9 [cited 2016 Nov 3];90(6):1097. Available from: http://www.journals.cambridge. org/abstract_S0007114503002290.

15. Østbye T, Malhotra R, Stroo M, Lovelady C, Brouwer R, Zucker N, et al. The effect of the home environment on physical activity and dietary intake in preschool children. Int J Obes (Lond) [Internet]. 2013 Oct [cited 2016 Nov 3];37(10):1314-21. Available from: http://www. pubmedcentral.nih.gov/articlerender.fcgi?artid 
$=3786032 \&$ too $\mathrm{I}=$ pmcentrez\&rendertype $=$ abstr act.

16. Mcintosh BA, Davis G, Nayga R, Anding J, Kubena K, Perusquia E, et al. Parental Time, Role Strain , and Children 's Fat Intake and ObesityRelated Outcomes. 2006.

17. Kim C, Park K, Park Y. Nutritional Status of Mentally Retarded Children by Residence and by Degree of Handicap. Korean J Community Nutr. 2003;8(1):112-9.

18. Dannhauser A, Walsh C. Nutritional Status of Disabled Schoolchildren in Bloemfontein (20022003). South African J Clin Nutr. 2007;2(1).

19. Tamin TZ, Idris FH, Mansyur M, Syarif DR. Prevalence and determinants of obesity in students with intellectual disability in Jakarta. Med J Indones. 2014;23(2):106-11.

20. Penagini F, Mameli C, Fabiano V, Brunetti D, Dilillo
D, Zuccotti GV. Dietary intakes and nutritional issues in neurologically impaired children. Nutrients. 2015;7(11):9400-15.

21. Al-Shookri A, Al-Shukaily L, Hassan F, Al-Sheraji S, Al-Tobi S. Effect of mothers nutritional knowledge and attitudes on Omani children's dietary intake. Oman Med J. 2011;26(4):253-7.

22. Scaglioni S, Salvioni M, Galimberti C. Influence of parental attitudes in the development of children eating behaviour. $\mathrm{Br} \mathrm{J}$ Nutr [Internet]. 2008;29(SUPPL.1):S22-5. Available from: http:// www. scopus.com/inward/record. url?eid=2s2.0-38949112770\&partnerID $=40 \& \mathrm{md} 5=\mathrm{c} 1 \mathrm{c} 3$ 1581f34950ecfbfc927d95f98cf3\nhttp://www. scopus.com/inward/record.url?eid=2-s2.038949112770\&partnerID=tZOtx3y1.

23. Marchand V. Nutrition in neurologically impaired children. Vol. 14. 2009. 